\title{
Comportamento produtivo de Cultivares de Morangueiro estabelecidos a partir de mudas com Torrão
}

${ }^{1}$ Michél Aldrighi Gonçalves, ${ }^{2}$ Carine Cocco, ${ }^{3}$ Gerson Kleink Vignolo,

${ }^{4}$ Luciano Picolotto, ${ }^{5}$ Luis Eduardo Corrêa Antunes

Secretaria Municipal de Desenvolvimento Rural - SMDR, Rua General Câmara, 1158, Canguçu, RS, CEP. 96600.000,

Canguçu, RS, Brasil. E-mail: aldrighimichel@gmail.com

${ }^{2}$ Universidade de Caxias do Sul, Rua Francisco Getúlio Vargas, 1130 CEP 95070-560, Caxias do Sul - RS, Brasil.

E-mail: ccocco@ucs.br

Embrapa Clima Temperado, Rodovia BR 392, Km 78, Pelotas, RS, CEP 96010-971, Pelotas, RS, Brasil.

E-mail: gerson_vignolo@yahoo.com.br

${ }^{4}$ Universidade Federal de Santa Catarina - UFSC, Campus de Curitibanos, Centro de Ciências Rurais,

Rodovia Ulysses Gaboardi, Km 3, CEP. 89.520-000, Curitibanos, SC, Brasil. E-mail: picolotto.1@ufsc.br

Embrapa Clima Temperado, Rodovia BR 392, Km 78, Pelotas, RS, CEP 96010-971, Pelotas, RS, Brasil. Bolsista CNPq.

E-mail: luis.antunes@embrapa.br

ISSN 2448-0479

Resumo - O presente estudo teve como objetivo caracterizar o comportamento de cultivares de morangueiro estabelecidas a partir de mudas com torráo "plug plants" na regiấo de Pelotas-RS. Foram utilizadas quatro cultivares de dias curtos 'Camarosa', 'Strawberry Festival', 'Oso Grande' e 'Camino Real'. As mudas foram obtidas por meio do sistema de produção com matrizes suspensas, onde as pontas dos estolóes foram enraizadas em substrato comercial. As mudas com torrão foram transplantadas para o campo de cultivo no dia 14 de abril de 2012. A cultivar 'Oso Grande' apresentou maiores valores de SS/AT nos picos produtivos de setembro e novembro $(11,34 \mathrm{e}$ 13,92 respectivamente) diferindo estatisticamente das demais cultivares. No primeiro mês de colheita (julho), as plantas de 'Strawberry Festival', 'Oso Grande' e 'Camarosa' apresentaram maior produçáo e número de frutos do que 'Camino Real'. As maiores massas médias de fruta nos meses de julho, agosto, setembro e outubro foram obtidas em frutas da cultivar 'Camino Real'. As cultivares 'Strawberry Festival' 'Camarosa' e 'Oso Grande' apresentaram elevada produção comercial total $\left(901,45 ; 850,45\right.$ e $801,14 \mathrm{~g} \cdot \mathrm{pl}^{-1}$, respectivamente). Nas condiçôes em que o estudo foi realizado foi possível concluir que as plantas das cultivares 'Camarosa', 'Strawberry Festival' e 'Oso Grande' estabelecidas com mudas com torrão apresentam elevadas produçôes precoces e totais e 'Camino Real' apresenta massa média de fruta superior as demais estudadas.

Palavras-chave - Precocidade. Dias curtos. Morango.
Abstract - This study aimed to characterize the behavior of strawberry cultivars established from transplants with plug plants in the Pelotas Rio Grande do Sul. Four varieties of short days were used 'Camarosa', 'Strawberry Festival', 'Oso Grande' and 'Camino Real'. The transplants were obtained through the production system with suspended arrays where the tips of stolons were rooted in commercial substrate. The transplants were transplanted with root ball for growing field on 14 April 2012. The cultivar 'Oso Grande' showed higher SS/TA values in production peaks in September and November (11.34 and 13.92 respectively) differing statistically the other cultivars. In the first month of harvest (July), the plants of 'Strawberry Festival', 'Oso Grande' and 'Camarosa' had higher production and number of fruits than 'Camino Real'. The highest average fruit weight in the months of July, August, September and October was obtained in fruits of cultivar 'Camino Real'. The cultivars 'Strawberry Festival', 'Camarosa' and 'Oso Grande' showed high total commercial production (901.45, 850.45 and $801,14 \mathrm{~g} \cdot \mathrm{pl}^{-1}$, respectively). The conditions under which the study was conducted it was concluded that the plant cultivars 'Camarosa', 'Strawberry Festival' and 'Oso Grande' established with plug plants have high early and total yield and the cultivar 'Camino Real' have an average mass higher fruit other studied.

Keywords - Precocity. Short days. Strawberry. 
Recebido em: 11 de maio de 2016.

Aprovado em: 12 de dezembro de 2016.

\section{INTRODUÇÃO}

No Brasil, a produção de morango é baseada em lavouras estabelecidas a partir de mudas frescas de raízes nuas provenientes de pontas de estolóes enraizadas diretamente no solo, sendo este o sistema tradicional de propagação (DAL PICIO et al., 2013). Entretanto, é comum observar que estas mudas são produzidas pelos próprios produtores de frutas em condições inadequadas, resultando em mudas de baixa qualidade. Pensando em reverter tal problema, nos ultimod anos os produtores têm buscado alternativas, sendo uma delas a importação de mudas de países como Argentina e Chile. Atualmente, as mudas oriundas destes países representam 30\% das mudas utilizadas no Brasil (ANTUNES; COCCO, 2012; ANTUNES; PERES, 2013). Tal fato vem gerando uma dependência dos produtores em relação às importaçôes, obrigando-os a adequar as datas de plantio das lavouras à época de chegada das mudas, a qual muitas vezes é fora do período recomendado (DAL PICIO et al., 2013).

Com a finalidade de reduzir a dependência dos produtores, e assim, proporcionar melhor aproveitamento e retorno econômico aos mesmos, a Embrapa Clima Temperado tem efetuado pesquisas que visam adequar a realidade brasileira a um sistema alternativo de produção de mudas denominado "Sistema de Produçáo de Mudas Fora de Solo". Este sistema proposto consiste na obtenção de pontas de estolóes para posterior produção de mudas enraizadas em bandejas (DURNER; POLING; MAAS, 2002; GIMÉNEZ; POLING; MAAS, 2008), também denominadas de mudas "plug plants". O sistema destaca-se por permitir a obtenção de mudas com rigoroso controle de qualidade sanitária e nutricional, além de elevado vigor, que são pré-requisitos essenciais para a obtenção de elevadas produtividades de frutas (COCCO et al., 2011).

Este sistema é vantajoso, pois permite escalonar a oferta das mudas, possibilitando assim a antecipação do plantio. Tal característica permite produçôes fora da época em que tradicionalmente a fruta é produzida, refletindo em um momento estratégico, do ponto de vista econômico para comercialização do morango, uma vez que este é o período de maior retorno econômico (ANTUNES et al., 2015). Algumas regiōes produtoras da Europa, já utilizam este tipo de muda de- vido ao seu ciclo de frutificação precoce (D'ANNA et al., 2014). Além desta característica, o plantio antecipado destas mudas é importante, pois permite prolongar o período produtivo da cultura (CARACCIOLO et al., 2009), garantindo uma fonte de renda aos produtores durante períodos alternativos.

Todavia, com a implantação de novos sistemas de produção de mudas, surge a necessidade de estudar o comportamento das cultivares tradicionalmente cultivadas nas mais diversas regióes. Sendo assim, o presente estudo objetivou caracterizar o comportamento de cultivares de morangueiro estabelecido a partir de mudas com torrão na região de Pelotas-RS.

\section{MATERIAIS E MÉTODOS}

O experimento foi conduzido durante os meses de abril a dezembro de 2012, na área experimental pertencente à Embrapa Clima Temperado, Pelotas-RS, cuja localização geográfica é de: $31^{\circ} 40^{\prime} \mathrm{S}$ e 52²6'W; $60 \mathrm{~m}$ de altitude. $\mathrm{O}$ solo da área experimental é um argissolo vermelho eutrófico típico, já o clima da regiáo pode ser classificado como temperado, com chuvas bem distribuídas ao longo do ano e veróes quentes.

Os tratamentos consistiram de quatro cultivares de morangueiro de dias curtos, sendo elas 'Camarosa', 'Camino Real', 'Strawberry Festival' e 'Oso grande'. As mudas para o plantio no campo foram produzidas em estufa agrícola, pertencente a Embrapa Clima Temperado, sendo adotado o sistema de produção fora do solo com matrizes suspensas cultivadas em calhas de PVC a partir de um sistema fechado com a utilizaçáo de casca de arroz carbonizada como substrato. As matrizes provenientes da cultura de tecidos foram transplantadas nos leitos de cultivo em meados de setembro de 2011 e emitiram estolóes durante a primavera e verão, período no qual as temperaturas são mais elevadas e o fotoperíodo longo, constituindo as condiçôes ideais para a propagação vegetativa.

As pontas de estolóes foram padronizadas conforme o diâmetro de coroa, de forma que foram utilizados aqueles com diâmetro entre 5 e $8 \mathrm{~mm}$, posteriormente enraizados em bandejas de 72 células com substrato comercial "HS Hortaliças" com capacidade de retençấo de água (CRA) de 140 e densidade de $500 \mathrm{Kg} / \mathrm{m}^{3}$. Após o plantio das pontas de estolăo nas bandejas, as mesmas permaneceram em câmara de nebulização intermitente, com frequência de irrigaçấo de 10 segundos a cada 5 minutos durante sete 
dias. Após este período, foram transferidas para as bancadas de crescimento (viveiro), onde foram mantidas durante 30 dias. Durante este período foram irrigadas por micro aspersão e fertirrigadas com solução nutritiva específica. Posteriormente, as mesmas foram expostas a 400 horas de frio em câmara fria adaptada (câmara de vernalização) com a temperatura de $4,0^{\circ} \mathrm{C}$ $\pm 0,1^{\circ} \mathrm{C}$, com luz artificial através de lâmpadas fluorescentes, sendo transplantadas para o campo no dia 14 de abril de 2012.

O sistema de produção adotado a campo foi de túneis baixos, amplamente difundido na região $\mathrm{Sul}$ do país. Os canteiros de cultivo apresentaram $1,2 \mathrm{~m}$ de largura por $0,25 \mathrm{~m}$ de altura, sendo o solo coberto com polietileno preto de $50 \mu \mathrm{m}$ e a cobertura dos túneis com polietileno transparente de $150 \mu \mathrm{m}$, próprios para o cultivo de hortaliças. A adubação de base foi de acordo com a recomendação da análise de solo e realizada com trinta dias de antecedência ao plantio das mudas, já a adubação de cobertura foi realizada via fertirrigação durante os picos de exigência, totalizando 17 aplicaçôes durante o ciclo.

O controle do aumento excessivo da temperatura, bem como a renovação do ar no interior dos túneis, foi realizado mediante a abertura lateral do plástico de revestimento nas primeiras horas da manhã e fechamento no entardecer. Em dias de chuva e ventos fortes, foram mantidos parcial ou totalmente fechados, dependendo das condiçóes climáticas. As demais práticas utilizadas obedeceram às premissas recomendadas no manual de Normas Técnicas e Específicas para a Produção Integrada de Morango.

As variáveis analisadas foram: sólidos solúveis (SS), obtido do suco de dez frutas de cada parcela com auxílio de um refratômentro digital (Atago DBX-55), com compensação de temperatura, cujo os valores foram expressos em ${ }^{\circ} \mathrm{Brix}$; potencial hidrogeniônico $(\mathrm{pH})$, obtido diretamente no suco com auxílio de um phgâmetro digital; acidez titulável (AT), expressa em $\%$ de ácido cítrico e obtida com auxílio de titulador automático; relação SS/AT. Estas variáveis foram analisadas em três períodos durante o ciclo produtivo, sendo o primeiro em julho (definido como o período de início das colheitas) e nos meses correspondentes aos picos produtivos (setembro e novembro).

Foi também avaliada a produção, obtida através do somatório, da massa fresca de frutas, sendo expressa em gramas (g) por planta; número médio de frutas, obtido através da soma do número de frutas de cada planta; massa média de fruta, expressa em gramas (g), sendo a mesma obtida pelo quociente entre a massa fresca de fruta e o número médio de frutas por planta, durante os períodos de avaliaçáo.

A colheita teve início no mês de junho, estendendo-se até 27 de dezembro do mesmo ano. A colheita foi padronizada com base na coloraçáo das frutas, sendo colhidas quando apresentavam 100\% da epiderme com coloração avermelhada, ou seja, no estádio de maturação completa. Para as avaliaçóes, foram contabilizadas apenas as frutas comerciais, sendo selecionadas com base na massa fresca. Frutas com defeitos graves ou massa fresca inferior a cinco gramas foram consideradas não comerciais e descartadas.

O delineamento experimental foi em blocos casualizados, com quatro blocos, sendo a unidade experimental composta por nove plantas. Os dados obtidos foram testados quanto a homocedasticidade e normalidade dos resíduos, sendo posteriormente submetidos à análise de variância, e as médias comparadas pelo teste de Tukey, ao nível de $5 \%$ de probabilidade de erro por meio do programa estatístico WinStat.

\section{RESULTADOS E DISCUSSÃO}

As plantas da cultivar 'Oso Grande' foram as que produziram frutas com maiores valores de SS nos três períodos de avaliação $(9,20 ; 6,22$ e 8,52 ${ }^{\circ}$ Brix, respectivamente). No mês de julho, 'Oso Grande' não diferiu de 'Strawberry Festival' e 'Camarosa', diferindo estatisticamente apenas de 'Camino Real'. Em setembro, período em que os valores de SS foram menores para todas as cultivares, 'Oso Grande' se destacou, seguida de 'Strawberry Festival', diferindo de 'Camino Real' e 'Camarosa'. Já em novembro, 'Oso Grande', 'Strawberry Festival' e 'Camarosa' foram semelhantes e diferiram estatisticamente de 'Camino Real'. As diferenças apresentadas sobre a variável em questáo entre os períodos de avaliação são consideradas normais. Pinelli et al. (2011) destacam como fatores de influência as condiçôes ambientais do período, a nutrição das plantas, assim como a cultivar. Samykanno, Pang e Marriott (2013) consideram que o teor de sólidos solúveis em morango, seja mais dependente das condiçóes ambientais durante o período de produção do que propriamente a cultivar. De uma forma geral, os teores de sólidos solúveis foram semelhantes entre as cultivares nos três períodos de avaliação, conforme exposto na Tabela 1. 
Tabela 1 - Sólidos solúveis (SS) orix, pH, acidez tilulável (AT) e relação SS/AT de frutos de quatro cultivares de morangueiro de dias curtos propagadas no sistema de produção de mudas fora do solo (torrão). Embrapa Clima Temperado. Pelotas-RS, 2014.

\begin{tabular}{lllll}
\hline & $\begin{array}{l}\text { SS } \\
\left({ }^{\circ} \text { Brix }\right)\end{array}$ & Ph & $\begin{array}{c}\text { AT(\% } \\
\text { ác.citr })\end{array}$ & SS/AT \\
Julho
\end{tabular}

ns não significativo, ${ }^{*}$ médias seguidas de letras minúsculas distintas na mesma coluna diferem entre si a 5\% de probabilidade de erro.

Tratando-se do $\mathrm{pH}$, observa-se que este não diferiu significativamente na primeira época de avaliação (julho), e apresentou pequenas variações entre as cultivares nas datas subsequentes, sendo que todos os valores variaram entre 3,32 a 3,72, com valores mais elevados para 'Oso Grande', principalmente em novembro. Concordando com Samykanno, Pang e Marriott (2013), que também testaram a influencia da cultivar no $\mathrm{pH}$. Vale ressaltar que a determinaçấo desta variável é importante, pois a mesma permite definir a finalidade de uso das cultivares, sendo frutas com $\mathrm{pH}$ ácido preferíveis para a indústrialização, enquanto um $\mathrm{pH}$ menos ácido é mais aceito para o consumo in natura.

As cultivares avaliadas não apresentaram diferença estatística para a variável acidez titulável (AT) na primeira data de avaliação (julho). Já em setembro e novembro, as frutas de 'Camarosa' mostraram-se mais ácidas ( 0,78 e $0,84 \%$ de ác. cítrico, respectivamente), não diferindo estatisticamente dos valores obtidos para 'Strawberry Festival' na última data de avaliaçâo (Tabela 1). Esta última diferiu de 'Oso Grande' em novembro, constatando menor acidez da mesma. A influência da cultivar na AT, também foi destacada por Samykanno, Pang e Marriott (2013), podendo estar ligado a características genéticas ou de variação no estágio de maturação, que pode estar associado ou não a cor da fruta. Aspecto que segundo Rahman et al. (2014) pode modificar a AT dos morangos.

A relação entre SS/AT é considerada por muitos pesquisadores, o parâmetro de maior relevância para indicar a qualidade de uma fruta. Mayer et al. (2008) assumem que esse índice indica o sabor dos frutos, mostrando melhor palatabilidade quanto maior for a relação SS/AT. Neste contexto, conforme observado houve efeito da cultivar, concordando com Samykanno, Pang e Marriott (2013). No presente trabalho a cultivar 'Oso Grande' se destacou entre as cultivares estudadas nas duas datas de pico de produção, apresentando uma relação SS/AT de 11,34 no mês de setembro e 13,92 no mês de novembro, diferindo estatisticamente das demais cultivares estudadas. Este comportamento está diretamente relacionado à baixa acidez e ao alto teor de SS que as frutas de 'Oso Grande' apresentaram nestas datas de avaliaçấo. Com isto, considera-se que dentre as cultivares estudadas, 'Oso Grande' é a cultivar que apresenta características palatáveis mais apreciáveis para ser destinada ao consumo in natura.

No que tange aos aspectos produtivos das plantas, observou-se que algumas iniciaram a produção em junho. Entretanto, como esta produçáo não foi representativa e uniforme, não superando $5 \%$ da produção total da parcela, considerou-se para fins estatísticos o mês de julho como sendo o início do período produtivo. A precocidade de produção é um ponto importantíssimo para os produtores da regiáo de Pelotas-RS, podendo a mesma variar entre as regióes de cultivo. Considerando a produção precoce para regiáo de estudo como a obtida até o último dia do mês de agosto podemos demonstrar a distribuição em percentual acumulado de produção a seguinte sequência 'Strawberry Festival' com 33,25\%, 'Camarosa' com 30,23\%, 'Oso Grande' com 29,20\% e 'Camino Real' com 24,66\% durante este período (Tabela 2).

Dividindo a produção em meses observamos que as plantas de 'Strawberry Festival', 'Oso Grande' e 'Camarosa' apresentaram maior produção e maior número de frutos que as plantas de 'Camino Real', durante o mês de julho. Vale salientar que todas as cultivares obtiveram uma produçâo considerável para o mês de julho. Em concordância com esta afirmação, Oliveira e Scivittaro (2011) 
obtiveram apenas 39,7g no primeiro mês de produção (agosto), em plantas de 'Camarosa' estabelecidas com mudas frescas de raízes nuas, enquanto no presente estudo a mesma cultivar apresentou uma produção média de $126,7 \mathrm{~g}$ por planta neste período (Tabela 2), comprovando a importância de se utilizar uma parte da lavoura com mudas frescas com torrão, possibilitando a obtenção de produçôes precoces e reduzindo o risco de perda assumido quando se utiliza apenas um tipo de muda (PALHA; ANDRADE; SILVA, 2002).

Tratando-se do número de frutas por planta, observa-se na Tabela 2 uma similariedade no comportamento das cultivares no primeiro mês. Nos meses de agosto, setembro, novembro e dezembro, 'Strawberry Festival' destacou-se, com valores médios de 11,63; 14,94; 21,22 e 10,87 frutas por planta, respectivamente. Já, em outubro 'Camarosa' produziu mais frutos por planta $(11,47)$ e em agosto os valores foram menores e diferiram estatisticamente de 'Strawberry Festival'. 'Oso grande' diferiu de 'Strawberry Festival' em dezembro, enquanto 'Camino Real' diferiu em julho, agosto, setembro e novembro, sendo a cultivar que apresentou menor média de número de frutos por planta ( 48,8 frutas), quando comparada à 'Strawberry Festival' $(74,94$ frutas), 'Camarosa' (64,36 frutas) e 'Oso Grande' (60,83frutas).

Para a variável massa média de fruta (Tabela 2), 'Camino Real' apresentou maior média nos meses de julho, agosto e outubro, no entanto neste último mês não diferiu significativamente de 'Camarosa' e 'Oso Grande', sendo que nos demais meses não houve diferença significativa entre as cultivares. Destaca-se o primeiro mês, em que a massa média de fruta variou de $29,52 \mathrm{~g}$ para 'Camino Real' a 18,94g para 'Strawberry Festival'. Este comportamento pode estar relacionado com o reduzido número de frutos nas plantas neste período, sendo que os primeiros frutos de cada florada do morangueiro são normalmente os maiores, pois são originados das flores primárias da inflorescência (NERI et al., 2012). Os valores médios da variável em questão confirmam que 'Camino Real' é a cultivar produtora de frutas de maior tamanho e com maior uniformidade durante todo o ciclo produtivo, uma vez que, com $17,51 \mathrm{~g}$ em média, diferiu das demais e sendo seguida por 'Camarosa' $(14,70 \mathrm{~g})$, 'Oso Grande' $(13,44 \mathrm{~g})$ e 'Strawberry Festival' (12,54g).
Com relação à produção, a cultivar 'Strawberry Festival' merece destaque, pois apresentou maior produção média nos dois primeiros meses de colheita $(129,51$ e $170,19 \mathrm{~g}$, respectivamente), diferindo apenas de 'Camino Real'. A produção precoce é a principal característica deste tipo de muda, sendo que no mês de julho é um dos meses em que o quilo do morango atinge o seu maior valor de mercado, segundo dados de comercializaçáo do CEASA/RS. Antunes et al. (2015) destacam que no período de entressafra, os preços podem ter um aumento de até $100 \%$ em relação à média geral. Nos meses que se seguiram até o final do ciclo produtivo, não ocorreram diferenças significativas entre as cultivares para a variável em questão.

As médias mensais de produçâo de cada cultivar permitiram constatar, de forma geral, a ocorrência de dois picos de produção (Tabela 2 ), sendo o primeiro registrado no mês de setembro e o segundo em novembro, nos quais os valores obtidos foram praticamente, duas vezes maiores que nos demais meses. O comportamento com dois picos produtivos demonstra que as plantas tiveram duas fases de indução floral bem distintas, a primeira provavelmente ainda na fase de formaçáo da muda e a segunda devido a exposição a condições climáticas indutivas no campo de cultivo (dias curtos e temperaturas baixas). No cultivo com mudas frescas de raizes nuas não é comum a observação de mais de um pico produtivo como descrito por Ristow et al. (2009), que observaram apenas um pico de produção no mês de novembro para cultivares de dias curtos. Uma hipótese para este comportamento seria a época de plantio mais favorável a uma determinada cultivar. Os resultados obtidos por que Rahman et al. (2014), corroboram com esta hipotese, sendo que os mesmos autores verificaram diferenças singinficativas na produção de distintas cultivares em quatro épocas de plantio.

O mês de dezembro marcou o final do ciclo produtivo de ambas as cultivares, perceptível pela acentuada queda na produção e qualidade dos frutos. Este evento fisiológico é normalmente verificado quando se trata de plantas de dias curtos cultivadas na regiāo de Pelotas-RS, pois as elevadas temperaturas e fotoperíodo acima de 14 horas verificados neste período, são os principais fatores que influenciam para a queda de produção e qualidade das frutas. 
Tabela 2 - Número médio de frutos (NMF), massa média de frutas (MMF), produção por planta $(\mathrm{P})$ e distribuição da produção em cada período (DP), em cultivares de morangueiro de dias curtos propagadas no sistema de produção de mudas fora do solo (torrão). Embrapa Clima Temperado, Pelotas/RS, 2014.

\begin{tabular}{|c|c|c|c|c|c|}
\hline & Cultivar & NMF & $\begin{array}{l}\text { MMF } \\
\left(\mathrm{g} . \mathrm{fr}^{-1}\right)\end{array}$ & $\begin{array}{l}\mathbf{P} \\
\left(\text { g.pl } \mathrm{l}^{-1}\right)\end{array}$ & $\begin{array}{l}\text { DP } \\
(\%)\end{array}$ \\
\hline \multirow{4}{*}{ Jul. } & Camarosa & $4,9 \mathrm{ab}^{*}$ & $25,7 b$ & $126,3 \mathrm{a}$ & 14,9 \\
\hline & $\begin{array}{l}\text { Camino } \\
\text { Real }\end{array}$ & $2,3 \mathrm{~b}$ & $29,5 \mathrm{a}$ & $67,0 \mathrm{~b}$ & 9,2 \\
\hline & S. Festival & $6,8 \mathrm{a}$ & $18,9 \mathrm{c}$ & $129,5 \mathrm{a}$ & 14,4 \\
\hline & Oso Grande & $5,3 \mathrm{ab}$ & $19,5 c$ & $104,3 \mathrm{ab}$ & 13,0 \\
\hline \multirow{4}{*}{ Ago. } & Camarosa & $7,3 \mathrm{~b}$ & $18,1 b$ & $130,9 \mathrm{ab}$ & 15,4 \\
\hline & $\begin{array}{l}\text { Camino } \\
\text { Real }\end{array}$ & $5,2 \mathrm{~b}$ & 21,9 a & $113,5 b$ & 15,5 \\
\hline & S.Festival & $11,6 \mathrm{a}$ & $14,6 c$ & $170,2 \mathrm{a}$ & 18,9 \\
\hline & Oso Grande & $8,1 \mathrm{ab}$ & $16,3 \mathrm{bc}$ & $129,7 \mathrm{ab}$ & 16,2 \\
\hline \multirow{4}{*}{ Set. } & Camarosa & $12,6 a b$ & $15,5^{\text {ns }}$ & $194,3^{\text {ns }}$ & 22,9 \\
\hline & $\begin{array}{l}\text { Camino } \\
\text { Real }\end{array}$ & $10,4 b$ & 17,1 & 175,2 & 23,9 \\
\hline & S.Festival & $14,9 \mathrm{a}$ & 13,9 & 207,2 & 22,9 \\
\hline & Oso Grande & $14,3 \mathrm{ab}$ & 14,3 & 203,2 & 25,4 \\
\hline \multirow{4}{*}{ Out. } & Camarosa & $11,5 \mathrm{a}$ & $10,8 \mathrm{ab}$ & $125,3^{\mathrm{ns}}$ & 14,7 \\
\hline & $\begin{array}{l}\text { Camino } \\
\text { Real }\end{array}$ & $6,8 \mathrm{~b}$ & 13,9 a & 94,0 & 12,8 \\
\hline & S. Festival & $9,3 \mathrm{ab}$ & $10,4 b$ & 96,9 & 10,9 \\
\hline & Oso Grande & $7,8 \mathrm{ab}$ & $11,4 a b$ & 89,3 & 11,2 \\
\hline \multirow{4}{*}{ Nov. } & Camarosa & $20,4 a$ & $10,5^{\mathrm{ns}}$ & $215,4^{\mathrm{ns}}$ & 25,3 \\
\hline & $\begin{array}{l}\text { Camino } \\
\text { Real }\end{array}$ & $14,9 b$ & 13,2 & 196,4 & 26,8 \\
\hline & S. Festival & $21,2 \mathrm{a}$ & 10,4 & 219,9 & 24,4 \\
\hline & Oso Grande & $19,6 a$ & 11,8 & 229,2 & 28,6 \\
\hline \multirow{4}{*}{ Dez. } & Camarosa & $7,7 \mathrm{ab}$ & $7,6^{\mathrm{ns}}$ & $58,4^{\mathrm{ns}}$ & 6,9 \\
\hline & $\begin{array}{l}\text { Camino } \\
\text { Real }\end{array}$ & $9,2 \mathrm{ab}$ & 9,3 & 85,9 & 11,7 \\
\hline & S. Festival & $10,9 a$ & 7,1 & 77,6 & 8,6 \\
\hline & Oso Grande & $5,8 \mathrm{~b}$ & 7,3 & 45,5 & 5,7 \\
\hline CV. & & 20,9 & 12,2 & 20,8 & \\
\hline \multirow{4}{*}{ Total } & Camarosa & $64,4 \mathrm{ab}$ & $14,7 b$ & $850,5 \mathrm{ab}$ & 100 \\
\hline & $\begin{array}{l}\text { Camino } \\
\text { Real }\end{array}$ & $48,8 \mathrm{c}$ & $17,5 \mathrm{a}$ & $732,1 b$ & 100 \\
\hline & S.Festival & $74,9 \mathrm{a}$ & $12,5 c$ & $901,5^{a}$ & 100 \\
\hline & Oso Grande & $60,8 b$ & $13,4 b c$ & $801,1 \mathrm{ab}$ & 100 \\
\hline $\mathrm{CV}$. & & 8,3 & 5,8 & 7,8 & \\
\hline
\end{tabular}

ns não significativo, *médias seguidas de letras minúsculas distintas na mesma coluna diferem entre si a 5\% de probabilidade de erro.

Algumas colocaçóes sobre o panorama geral das variáveis analisadas são importantes, pois permitem relacionar as informaçóes obtidas no estudo. Neste contexto, é possível constatar (Tabela 1) que a qualidade das frutas se destaca na cultivar 'Oso Grande', por apresentar uma relaçáo SS/AT mais alta nos dois últimos períodos de avaliação (11,34 e 13,92, res- pectivamente), demonstrando melhores características palatáveis. Já no que se refere à produção de frutas, 'Strawberry Festival' e 'Camarosa' apresentam maior número de frutas por planta $(74,94$ e 64,36, respectivamente), enquanto 'Camino Real' foi a cultivar com maior massa média de frutas $(17,51 \mathrm{~g})$. Sobre a produção total de frutas, é possível afirmar que todas as cultivares apresentaram produção satisfatória, 'Strawberry Festival' produziu 901,45g por planta, 'Camarosa' 850,45 g por planta e 'Oso Grande' $801,14 \mathrm{~g}$ por planta, não diferindo estatisticamente entre si. Destacando que as mudas com torrão proporcionaram a obtenção de produção precoce, característica esta já verificada por D'anna et al. (2014) no Sul da Itália e por Gimenez et al. (2009) na região central do Rio Grande do Sul. Os 850,45g obtidos com a cultivar 'Camarosa' no presente estudo são semelhantes ao obtido por Ristow et al. (2009) que obtiveram em Pelotas-RS 877,51g por planta e superam os valores descritos por Oliveira e Scivittaro (2011), que cultivando 'Camarosa' também em Pelotas-RS, obtiveram 740,2g por planta com mudas importadas.

\section{CONCLUSÁO}

As cultivares 'Camarosa', 'Strawberry Festival' e 'Oso Grande' estabelecidas com mudas com torráo nas condiçóes edafoclimáticas de Pelotas-RS, apresentam elevadas produçôes precoces e totais e 'Camino Real' elevada massa média de fruta.

\section{AGRADECIMENTOS}

Os autores agradecem o apoio financeiro recebido da Coordenação de Aperfeiçoamento de Pessoal de Nível Superior (CAPES) e do Conselho Nacional de Desenvolvimento Científico e Tecnológico (CNPq).

\section{REFERÊNCIAS}

ANTUNES, L.E.C. et al. Morangos do jeito que o consumidor gosta. Campo \& Lavoura, Anuário HF, v. 1, n. 64-72. 2015.

ANTUNES, L.E.C.; PERES, N.A. Strawberry production in Brazil and South America. International Journal of Fruit Science, v.13, n.1-2, p.156-161. 2013.

ANTUNES, L.E.C.; COCCO, C. Tecnologia 
apara a produção de frutas e mudas do morangueiro. Agropecuária Catarinense, v.25, n.2, p. 61-65. 2012.

CARACCIOLO, G. et al. Effects of Planting Dates on Strawberry Plug Plant Performance in Sicily. Acta Horticulturae, v. 842, p. 155-158, 2009.

COCCO, C. et al. Crown size and transplant type on the strawberry yield. Scientia Agricola, v. 68, p. 489-493. 2011.

D'ANNA, F. et al. Effects of Plant Type on Two Strawberry Cultivars in Sicily. Acta Horticulturae, v. 149, p. 553-556. 2014.

DAL PICIO, M. et al. Fruit yield of strawberry stock plants after runner tip production by different cultivars. Horticultura Brasileira, v.31, p.375-379, 2013.

DURNER, E.F.; POLING, E.B.; MAAS, J.L. Recent advances in strawberry plug transplant technology. HortTechnology, v.12, p.545- 550, 2002.

GIMÉNEZ, G.; ANDRIOLO, J.L.; GODOI, R.S. Cultivo sem solo no morangueiro. Ciência Rural, v.38, p. 273-279, 2008.

GIMÉNEZ, G. et al. Cell size in trays for the production of strawberry plug transplants. Pesquisa Agropecuária Brasileira, v.44, p.726-729, 2009.

NERI, D. et al. Strawberry production in forced and protected culture in Europe as a response to climate change. Canadian Journal Plant Science, v. 92, p.1021-1036, 2012.

OLIVEIRA R.P.; SCIVITTARO, W.B. Desenvolvimento produtivo de cultivares de morangueiro. Scientia Agraria, v.12, p.069-074, 2011.

PALHA, M.G.S.; ANDRADE, M.C.S.; SILVA, M.J.P. The effects of different types of plant production on strawberry yield and fruit qualiy. Acta Horticulturae, v.567, p. 515-518, 2002.

PINELLI, L.D.L.D.O. et al. Antioxidants and other chemical and physical characteristics of two strawberry cultivars at different ripeness stages. Journal of Food Composition and Analysis, v.24, p.11-16, 2011.

RAHMAN, M. M. et al. Maturity stages affect the postharvest quality and shelf-life of fruits of strawberry genotypes growing in subtropical regions. Journal of the Saudi Society of Agricultural Sciences, p. 1-10, 2014.
RISTOW, N.C. et al. Characterization of Strawberry Cultivars in Southern Brazil. Acta Horticulturae, v.842, p. 515-518. 2009.

SAMYKANNO, K.; PANG, E.; MARRIOTT. P.J. Genotypic and environmental effects on flavor attributes of 'Albion' and 'Juliette' strawberry fruits. Scientia Horticulturae, v.164, p. 633-642. 2013. 